\title{
Differential Expression of Prokineticin Receptors by Endothelial Cells Derived from Different Vascular Beds: a Physiological Basis for Distinct Endothelial Function
}

\author{
Helena Podlovni ${ }^{1}$, Oded Ovadia ${ }^{1}$, Tatiana Kisliouk ${ }^{1}$, Eyal Klipper ${ }^{1}$, \\ Qun-Yong Zhou ${ }^{2}$, Aharon Friedman ${ }^{3}$, Nadia Alfaidy ${ }^{4}$ and Rina Meidan ${ }^{1}$
}

Sections of ${ }^{1}$ Reproductive Endocrinology and ${ }^{3}$ Immunology, Department of Animal Sciences, Faculty of Agricultural, Food and Environmental Quality Sciences, The Hebrew University of Jerusalem, Rehovot ${ }^{2}$ Department of Pharmacology, University of California, Irvine, ${ }^{4}$ INSERM EMI 105, DSVSUD, CEA. de Grenoble

\section{Key Words}

Luteal endothelial cells $•$ Bovine aortic endothelial cells

- Endothelial permeability • Brain capillaries • Apoptosis

- Endothelial phenotypic heterogeneity

\begin{abstract}
Prokineticins (PKs), multifunctional secreted proteins, activate two endogenous $G$ protein-coupled receptors (R) termed PK-R1 and PK-R2. It was suggested that PK1 acts selectively on the endothelium of endocrine glands, yet PK-Rs were also found in endothelial cells (EC) derived from other tissues. Therefore we examined here the characteristics of PK - system in EC derived from different vascular beds. Corpus luteum (CL)-derived EC (LEC) expressed both PKR1 and PK-R2. In contrast, EC from the aorta (BAEC) only expressed PK-R1. Interestingly, also EC from brain capillaries (BCEC) expressed only PK-R1. The distinct pattern of PK-R expression may define EC
\end{abstract}

\section{KARGER}

Fax +41613061234

E-Mail karger@karger.ch

www.karger.com
(C) 2006 S. Karger AG, Basel

$1015-8987 / 06 / 0186-0315 \$ 23.50 / 0$

Accessible online at:

www.karger.com/journals/net phenotypic heterogeneity. Regulation of receptor expression also differed in BAEC and LEC: TNF $\alpha$ markedly reduced PK-R1 only in BAEC, but serum removal decreased PK-R1 in both cell types. Therefore, if cells were initially serum-starved, the antiapoptotic effect of PKs was retained only in LEC. Yet, addition of PKs concomitant with serum removal enhanced the proliferation and survival of both BAEC and LEC. Immunohistochemical staining showed that in CL and aorta PK1 was expressed in smooth muscle cells in vessel walls, suggesting a paracrine mode of action. PK1 enhanced the net paracellular transport (measured by electrical resistance and Mannitol transport) in LEC but not in BAEC or BCEC. Collectively, these findings indicate that PKs serve as mitogens and survival factors for microvascular (LEC) and macrovascular (BAEC) EC. However, the distinct expression and function of $\mathrm{PK}$ receptors suggest different physiological roles for these receptors in various EC types.

Copyright () 2006 S. Karger AG, Basel

\footnotetext{
Rina Meidan

Dept Animal Sci, Faculty of Agricultural, Food and Environmental Quality Sciences The Hebrew University of Jerusalem, Rehovot 76100 (Israel) Tel. +972-89489394, Fax +972-89465763

E-Mail rina.meidan@huji.ac.il
} 


\section{Introduction}

Prokineticin (PK) - 1 is a newly discovered protein $[1,2]$. Together with its close homolog, PK2, these secreted proteins belong to a family of peptides consisting of 80-90 amino acids, including 10 conserved cysteins, which create a five-disulphide-bridged motif (colipase fold) and identical N-termini sequence - AVIT [1-3].

PK1 is widely expressed in steroidogenic glands (such as the ovary, testis, placenta and adrenal gland), as well as in the gastrointestinal tract and the nervous system $[2,4-8]$.

The two PKs serve as cognate ligands for two closely homologous $G$ protein-coupled receptors (GPCRs) termed PK receptors (PK-R1 and PK-R2). Located in different chromosomes, these two receptors share $85 \%$ homology, which is a high value among known GPCRs [9-11]. PK1 and PK2 bind and activate their receptors indiscriminately with similar affinities [9-11]. In cells overexpressing either PK-R1 or R2, PKs mobilized calcium, stimulated phosphoinoside turnover, and activated the p44/p42 MAPK cascade [9-11]. These biological effects were also observed in cells naturally expressing PK - Rs, namely the adrenal cortex - derived endothelial cells (EC) and luteal EC (LEC) $[12,13]$.

Originally identified as an agent with the ability to contract gastrointestinal smooth muscle [1], PK1 was subsequently shown to also act as a selective angiogenic mitogen: intra-ovarian delivery of PK1 promoted angiogenesis and cyst formation in the rat ovary [2]. Moreover, it induced proliferation, migration and fenestration of EC derived from adrenal capillaries [2, 12]. Therefore, PK1 was also termed endocrine glandVEGF (EG-VEGF), although structurally it is unrelated to VEGF. We have recently reported that similarly to adrenal gland derived EC, PKs enhanced the proliferation and inhibited apoptosis in bovine luteal EC [13].

Endothelial cells are unique multifunctional cells that have numerous paracrine and endocrine functions (for review see [14]) some of which are to regulate homeostasis, vasomotor tone, permeability, and inflammatory responses. These properties vary both in space and time, giving rise to the phenomenon termed EC heterogeneity $[15,16]$. Using DNA microarrays, Chi et al. [17] showed that EC from different blood vessels in various tissues have distinct and characteristic gene expression profiles.

To better understand the role of these novel endothelial regulators, we determined the expression of PK receptors in EC derived from different vascular beds, an endocrine gland - the corpus luteum (CL), the aorta and brain. We then determined the response of EC from aorta and CL to PKs, explored the cell source of PK1 in these tissues, and finally determined the effects of PK1 on endothelial permeability.

\section{Materials and Methods}

\section{Materials}

Cell media: Dulbecco's Modified Eagle's Medium - (DMEM-F12 (1:1)), DMEM low (1 gr/L glucose), DMEM high (4.5g/L glucose), Hanks balanced salts solution (HBSS), L-Glutamine, Calf Serum (CS), Penicillin - Streptomycin solution, crystalline trypsin solution ( $0.2 \mathrm{~g} / \mathrm{L}$ trypsin), Trypsin EDTA solution $(2.5 \mathrm{~g} / \mathrm{L}$ trypsin, $0.2 \mathrm{~g} / \mathrm{L}$ EDTA), XTT proliferation kit were all obtained from Biological Industries (Kibbutz Beit Haemek, Israel). Vitrogen - type I collagen was purchased from Cohesion Technologies (Palo Alto, CA). Bovine serum albumin (BSA), 4',6-diamidino-2phenylindole dihydrochloride (DAPI), proteases inhibitor cocktail, D-Mannitol-[1-3H(N)] 1mCi/ml, acrylamide/bisacrylamide electrophoresis reagent $40 \%$ solution, paraformaldehyde and horseradish peroxidaseconjugated goat anti-rabbit IgG, and Mounting solution were acquired from Sigma (St. Louis, MO). [methyl$\left.{ }^{3} \mathrm{H}\right]$ thymidine was purchased from Amersham Biosciences (Buckinghamshire, UK). TRI Reagent was obtained from MRC (Cincinnati, OH). Fetal Bovine Serum (FBS), SuperScriptTM II RNase H- Reverse Transcriptase, and Ultrapure Electrophoresis Agarose were obtained from Invitrogen Corporation (Paisley, Scotland, UK). Random hexamer oligodeoxynucleotides were procured from Fermentas (Vilnius, Lithuania). Deoxynucleotide triphosphates were obtained from Bioline GmbH (Luckenwalde, Germany). Oligo-dT and Oligonucleotide primers were synthesized by MWG Biotech AG (Ebersberg, Germany). The Real-time PCR SYBR Green Master-Mix Kit was purchased from Eurogentec (Seraing, Belgium). Rabbit anti-p-44/42 MAPK was obtained from Cell Signaling Technology (Beverly, MA). Antiserum raised against the human PK1 peptide (residues 84-96: LLCSRFPDGRYRC) was from Covalab (Lyon, France). Recombinant human tumor necrosis factor- $\alpha$ (TNF- $\alpha$ ) were obtained from ProSpec - TanyTechnoGene Ltd. (Rehovot, Israel). SuperSignal West Pico Chemiluminescent Substrate was purchased from Pierce (Rockford, IL). Type I collagen-coated Transwell polystyrene filters, $1 \times 10^{5} /$ filter (surface area, 


\begin{tabular}{rlc}
\hline Gene & \multicolumn{1}{c}{ Sequence } & Product length (bp) \\
\hline G3PDH & $\begin{array}{l}\text { f: cgtggacagtggtcataagt } \\
\text { r: ggcgtgaaccacgagaagtat }\end{array}$ & 141 \\
& $\begin{array}{l}\text { f: ggtcatggatgagaatgcca } \\
\text { r: atacccaccagcgecatgcc }\end{array}$ & 200 \\
PK-R1 & $\begin{array}{l}\text { f: atacccaagaacatgcct } \\
\text { r: ctgatacccacaagtgccacc }\end{array}$ & 150 \\
\hline
\end{tabular}

Table 1. Real-time PCR primer list

$0.33 \mathrm{~cm}$; pore size, $0.4 \mathrm{~mm}$; Corning Costar, Cambridge, MA, USA). X-ray films were from Fuji Photo Film Co., Ltd. (Tokyo, Japan). DAKO anti-rabbit EnVision ${ }^{\mathrm{TM}}$ HRP Labelled Polymer and 3-amino-9-ethylcarbazole chromogen (AEC) were obtained from DakoCytomation (Carpinteria, CA).

\section{Endothelial cell cultures}

Luteal Endothelial Cells, isolation and culture: Isolation of LEC was performed as described by SpanelBorowski et al, [18] with slight changes. Briefly, bovine mid-cycle CLs were collected from a local slaughterhouse and luteal stage was determined by macroscopic examination of the ovaries, according to criteria described by M. Fields [19]. First, the surrounding tissue was removed and CLs were washed several times. Next, the CLs were thinly sliced using a device containing 20 parallel razor blades. The pieces were collected, centrifuged, and resuspended in medium following vigorous pipetting. The tissue was sieved through a 150$\mu \mathrm{m}$ pore size metal sieve and then through a $20-\mu \mathrm{m}$ pore size nylon mesh. Cells were centrifuged and resuspended in erythrocyte lysis buffer $\left(0.144 \mathrm{mM} \mathrm{NH}_{4} \mathrm{Cl} / 0.017 \mathrm{M}\right.$ Tris- $\mathrm{HCl}, \mathrm{pH}=7.4)$. Finally, the cells were seeded on Vitrogen type I - coated 24 -well plates $(500 \mu \mathrm{l} /$ well). The medium was changed every other day. Colonies appeared after 7-14 days; each was collected separately and their identity was verified by vWF staining and CD31 expression. LEC were cultured in DMEM-F12 containing $10 \%$ FBS, $2 \mathrm{mM}$ glutamine. Preliminary studies had shown that expression of PK-Rs and mitogenic response to PKs remained similar at least until passage 12; therefore, cells from passages 4-12 were used for these experiments. At least three independent cell isolates used in each experiment. Bovine Aortic Endothelial Cells (BAEC) and Brain (Capillary Endothelial Cells (BCEC) were kindly provided by Prof. Israel Vlodavsky (Hadassah-Hebrew Medical Center, Jerusalem, Israel).

Prokineticins and Endothelial Cells
BAEC and BCEC (passages 6-13) were cultured in low glucose DMEM containing $10 \% \mathrm{CS}$ and $2 \mathrm{mM}$ glutamine. When indicated, cells were starved in medium containing $0.1 \%$ serum and $0.5 \%$ BSA.

\section{RNA isolation and Real-time PCR}

Total RNA was isolated from the cells with TRIReagent according to the manufacturer's instructions. Quantitative real time PCR reactions were performed using PE Biosystems' GeneAmp 5700 sequence detection system, with the SYBR Green I PCR kit used as described by Klipper et al [20]. Briefly, each real-time reaction $(18 \mu 1)$ contained the SYBR Green Master Mix that comprised ROX passive reference, $200 \mu \mathrm{M}$ dNTPs including dUTP, $5 \mathrm{mM} \mathrm{MgCl}_{2}$, uracil $\mathrm{N}$-glycosylase, and Amplitaq HotGoldStar DNA polymerase; $0.54 \mu 1$ of a 1:10,000 dilution of SYBR Green stock solution; $1.5 \mathrm{mM}$ dNTPs; $10 \mathrm{nM}$ of each of the primers and 25-50 ng cDNA. The glyceraldehyde 3-phosphate dehydrogenase (G3PDH) gene was used as a standard. Dissociation curve analysis was run following each real-time experiment to confirm the presence of only one product and the absence of the formation of primer dimmers. The threshold cycle number $\left(\mathrm{C}_{\mathrm{T}}\right)$ for each tested gene $\mathrm{X}$ was used to quantify the relative abundance of the gene: $2^{-(\mathrm{Ct} \text { gene } \mathrm{X}-\mathrm{CtG} 3 \mathrm{PDH})} \times 1000$. For a list of primers, see Table 1.

\section{$\left[{ }^{3} \mathrm{H}\right]$-thymidine incorporation}

Incorporation of $\left[{ }^{3} \mathrm{H}\right]$-thymidine was measured according to Masuda et al. [10]. Briefly, LEC and BAEC were incubated for $32 \mathrm{~h}$ in 24-well plates in medium containing $0.5 \%$ BSA and $0.1 \%$ serum only or medium containing either $50 \mathrm{nM} \mathrm{PK} 1$ or PK2. $\left[{ }^{3} \mathrm{H}\right]$-thymidine (1 $\mu \mathrm{Ci} /$ well) was added during the last $8 \mathrm{~h}$ of incubation. The cells were then washed with cold HBSS and incubated with $10 \%$ trichloroacetic acid at $4^{\circ} \mathrm{C}$ for 15 min. The acid-insoluble fraction was dissolved in $0.3 \mathrm{~N}$ 
$\mathrm{NaOH}\left(15 \mathrm{~min}\right.$ at $\left.37^{\circ} \mathrm{C}\right)$ and the radioactivity was evaluated with a scintillation counter.

\section{XTT assay}

LEC and BAEC were seeded at 20,000 - 30,000 cells/well in 24 well plates with following addition of PK$1(50 \mathrm{nM})$ in medium containing $0.5 \%$ BSA and $0.1 \%$ serum. After 3 days of incubation the medium was replaced to basal medium ( $0.5 \% \mathrm{BSA}, 200 \mu \mathrm{l} /$ well), and $100 \mu 1$ of activated XTT reagent was added to each well. The cells were then incubated for $4 \mathrm{~h}$ at $37^{\circ} \mathrm{C}$. The absorbance was read at $450 \mathrm{~nm}$. From each value a blank (empty well reading) was subtracted and a number metabolically active cells was evaluated by dividing the mean of treated wells by mean of control $(n=3$ for each treatment or control).

\section{Immunohistochemistry}

Tissues (CLs at the mid cycle and slices of aorta) were fixed in $4 \%(\mathrm{v} / \mathrm{v})$ paraformaldehyde, embedded in paraffin, and cut into $5 \mu \mathrm{m}$ sections. The sections were de-waxed in xylene and rehydrated using decreasing ethanol concentrations. Endogenous peroxidase activity was quenched by pretreatment with $3 \%(\mathrm{v} / \mathrm{v})$ hydrogen peroxide in methanol for $30 \mathrm{~min}$. Antigen retrieval was performed by treating sections for $5 \mathrm{~min}$ in a microwave in boiling $0.1 \%$ citrate buffer ( $\mathrm{pH} 6.0$ ). Tissue sections were then washed in PBS and incubated with normal horse serum $(10 \%)$ that served as a blocking agent for non-specific binding for $1 \mathrm{~h}$. The serum containing PK1 rabbit polyclonal antibody (1:50 dilution in blocking solution) was added for 18h [6]. After 3 PBS washes, the slides were incubated with DAKO anti-rabbit EnVision $^{\mathrm{TM}}$ - HRP labeled Polymer for $30 \mathrm{~min}$. The immunoreactive proteins were visualized after addition of AEC solution for $5 \mathrm{~min}$ and then counterstained with hematoxylin.

\section{Immuno (Western) blotting}

Detection of $p 44 / 42$. Proteins were extracted from BAEC with SDS-lysis buffer $(62.5 \mathrm{mM}$ Tris- $\mathrm{HCl}, \mathrm{pH}$ $6.8,2 \%$ SDS, $10 \%$ glycerol, $50 \mathrm{mM}$ DTT, $0.01 \%$ bromophenol blue) and were sonicated for $10 \mathrm{~s}$. Protein extracts were separated on $12 \%$ SDS-polyacrylamide gel and transferred to nitrocellulose membranes. The membranes were blocked in TBST (20 mM Tris, $\mathrm{pH}$ 7.4, $150 \mathrm{mM} \mathrm{NaCl}, 0.05 \%$ Tween-20) containing 5\% nonfat milk for $1 \mathrm{~h}$ at room temperature, and were incubated overnight with either phosphorylated p42/p44 MAPK or total p42/p44 MAPK antibodies diluted in
TBST-5\% BSA (1:10,000 and 1:1000, respectively) at $4{ }^{\circ} \mathrm{C}$. The membranes were washed and then incubated with horseradish peroxidase-conjugated goat anti-rabbit IgG diluted in TBST-5\% nonfat milk at room temperature for $2 \mathrm{~h}$. A chemiluminescent signal was generated with SuperSignal and the membranes were exposed to X-ray film.

\section{DAPI staining}

LEC and BAEC were grown for $48 \mathrm{~h}$ in DMEMF12 containing $0.1 \% \mathrm{FBS}$ and $0.5 \% \mathrm{BSA}$, alone or with PKs (100 nM), on cover slips that had been precoated with $1 \%$ vitrogen up to $70-80 \%$ confluence. The cells were fixed with EFA $(70 \%$ ethanol, $4 \%$ paraformaldehyde, $5 \%$ glacial acetic acid), permeabilized with $0.25 \%$ Triton X-100 in PBS and then stained with 1 $\mu \mathrm{g} / \mathrm{ml}$ DAPI reagent [21]. The cover slips were mounted on glass slides and photographed under a fluorescent microscope. Apoptotic cells had condensed and fragmented nuclei [21]. For the analyses, 11-15 fields of view at $x 640$ magnification were quantified (15-20 cells per field) in each experiment. The percentage of apoptotic cells in each field was evaluated and the average over all fields was determined.

\section{Production of $P K 1$ and $P K 2$}

Production, refolding, and purification of recombinant PK1 and PK2 were carried out appropriately as described previously [1]. The activity of PK was further confirmed by calcium mobilization assay in $\mathrm{CHO}$ cells that stably expressed human PK-R1 or PK-R2 (9).

\section{Measurement of endothelial monolayer permeability}

A) Electrical resistance [22]. Different EC types (LEC, BAEC and BCEC) were seeded onto Vitrogencoated Transwell polystyrene filters, and grown to confluence for 10-11 days; growth medium was replaced every other day. Twenty-four hours prior to the experiment, confluent endothelial monolayers were serum-starved. Experiments were initiated by washing the upper and lower compartments with warmed $\left(37 \mathrm{C}^{\circ}\right)$ $20 \mathrm{mM}$ Tris-buffered saline, $\mathrm{pH} 7.4$, supplemented with $25 \mathrm{mM}$ glucose and $0.1 \%$ BSA ( $150 \mu \mathrm{l} /$ upper and $600 \mu \mathrm{l} /$ lower compartments). The inserts were allowed to equilibrate for $30 \mathrm{~min}$ at $37^{\circ} \mathrm{C}$ before initiating the experiments. After equilibration, the buffer was removed from the inserts and fresh buffer containing various treatments were added to the upper compartment (100U/ $\mathrm{ml}$ Thrombin, 75nM PK1/PK2). PK1, PK2, and

Podlovni/Ovadia/Kisliouk/Klipper/Zhou/Friedman/Alfaidy/Meidan 
Fig. 1. PK-R1 and PK-R2 expression in endothelial cells. Numbers (means \pm SEM) represent PK-R1 and PK-R2 mRNA expression determined by RealTime PCR. Data were from 3 independent cell preparations. Means with no common letters (uppercase for PK-R1 and lowercase for PK-R2) differ significantly $(\mathrm{p}<0.05)$.

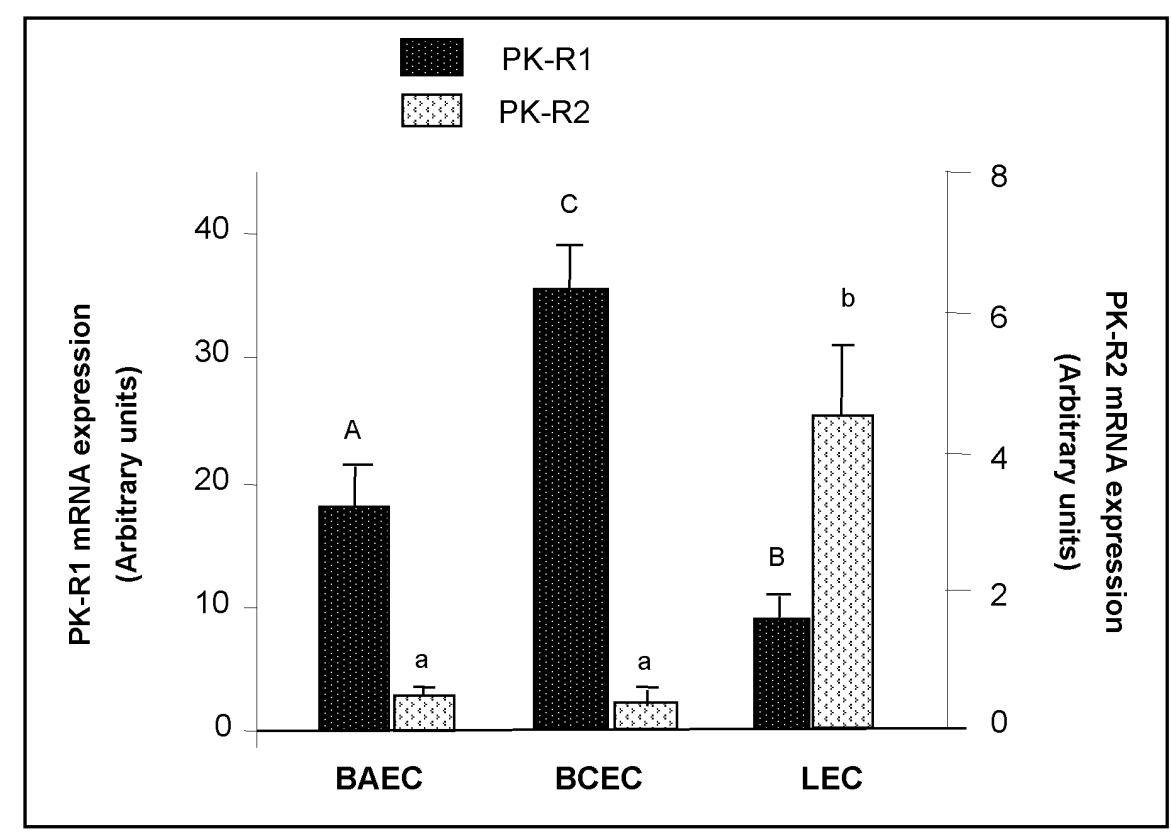

thrombin-induced changes in the resistance of the endothelial monolayers were measured using MilliCell ${ }^{\circledR}$ ERS (Millipore, MA USA) at 0, 5, 10, 15, 20, 25, and 35 minutes after adding the various treatments. Assays were performed in triplicate and changes in resistance were normalized to their respective controls.

B) $\left[{ }^{3} H\right]$ Mannitol transport (Papp) [23, 24]. Different EC types (LEC, BAEC and BCEC) were grown and treated as described in the previous section. Following the addition of the various treatments, the tracer $\left(\left[{ }^{3} \mathrm{H}\right]\right.$ Mannitol, $125 \mathrm{nCi} /$ well $)$ was added. Samples $(20$ $\mu 1)$ from the abluminal side were removed at 5, 10, 15, $20,25,35$, and 45 min and replaced with freshly warmed buffer. The assay was performed in triplicates. Radioactivity was measured using a $\beta$ counter. Papp $(\mathrm{cm} /$ s) was calculated using the following equation: Papp = $\mathrm{dQ} / \mathrm{dt} \times 1 / \mathrm{Ax}$ Co, where $\mathrm{dQ} / \mathrm{dt}$ is the slope of the linear curve describing the cumulative amount of tracer transported (i.e. detected in the abluminal side) vs time [sec], A, the surface area of the filter $(\mathrm{cm} 2)$, and $\mathrm{C} 0$ (units $/ \mathrm{ml}$ ), the initial concentration in the donor (luminal side).

\section{Statistical analyses}

Data are presented as means \pm SEM. All statistical analyses were carried out using JMP 5.1 ${ }^{\mathrm{TM}}$ (Statistical Software, SAS Institute). One-way ANOVA LSMeans Student's test was used to determine the statistical difference between treatments, as indicated in the results and the legends to the figures. Additionally, CONTRASTtest was used to evaluate the effect of serum withdrawal

Prokineticins and Endothelial Cells on PK-Rs expression in LEC and BAEC. Differences were considered significant at $P<0.05$.

\section{Results}

$P K-R m R N A$ expression and biological responses to $P K s$ in endothelial cell types: BAEC, BCEC and $L E C$

We initially determined the expression, regulation of expression and biological responses of PK-Rs in two EC types: LEC derived from the corpus luteum that contains mainly microvascular vessels and BAEC - a well characterized model for a macrovessel. Data presented in Fig. 1 show that LEC expressed both PKR1 and PK-R2, whereas BAEC expressed mainly PK$\mathrm{R} 1$; their levels in BAEC were significantly higher than in LEC. Interestingly, the profile of PK-R expression in another microvascular EC - BCEC, resembled that of BAEC (macrovascular) more than that of LEC (microvascular cells; Fig. 1). In fact, amongst these three cell types, BCEC expressed highest levels of PK-R1 mRNA and were practically devoid of PK-R2.

The effect of the two PKs on the survival of LEC and BAEC in conjunction with serum withdrawal was then evaluated. The addition of PK1 or PK2 to either BAEC or LEC in growth medium containing a low serum concentration $(0.1 \%)$ significantly increased cell survival as compared to controls ( $<<0.05$; Fig. $2 \mathrm{a}, 2 \mathrm{~b}$ "no starvation"). However, if cells were first incubated in starvation medium (without PKs) for 48 hours, and PKs

Cell Physiol Biochem 2006;18:315-326 


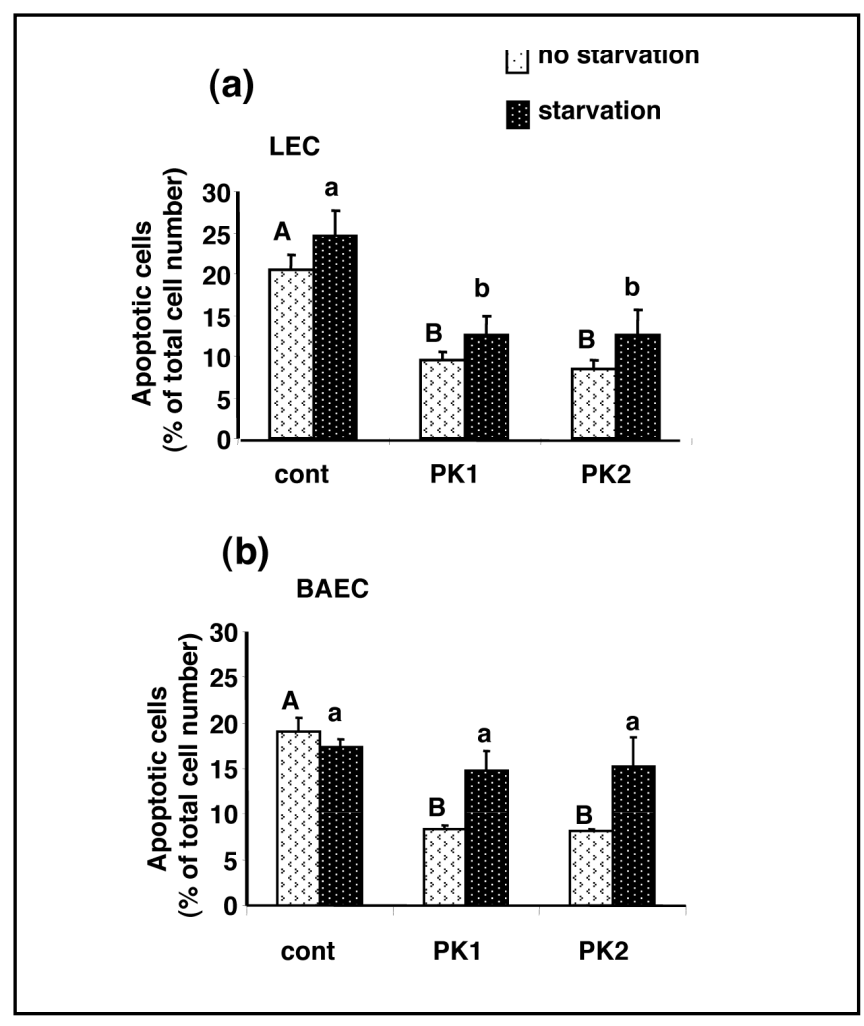

Fig. 2. Effect of PKs on the survival of LEC (a) and BAEC (b). Cells were either cultured for 48 hours with PKs added concomitantly with serum removal (,no starvation“) or cells were initially incubated in starvation medium (without PKs) for 48 hours, and PKs were added only during the following 48-h incubation period (,starvation“). The percentage of apoptotic nuclei was evaluated as described in „Materials and Methods“. Data represent means \pm SEM from 3 independent experiments. Means with no common letters differ significantly $(\mathrm{p}<0.05)$.

were then added for the following $48 \mathrm{~h}$ incubation period, different effects were produced in the two cell types. Under these conditions, PKs reduced the number of apoptotic cells only in LEC and not in BAEC (Fig. 2a, 2b "starvation").

We have previously shown that PKs augment the proliferation of LEC [13]. The data presented in Fig. 3a now show that the two PKs also markedly increased $\left[{ }^{3} \mathrm{H}\right]$-thymidine incorporation by approximately 1.6 -fold in BAEC. Similarly, the XTT assay that determines cell proliferation by the colorimetric oxidative conversion of a tetrazolium salt (XTT) by metabolically active cells, showed that PK1 significantly increased cell numbers by a factor of 1.4.

We then examined whether PKs activated p44/42 MAPK in these cells. The MAPK pathway is a wellrecognized signaling mechanism that mediates numerous (a)

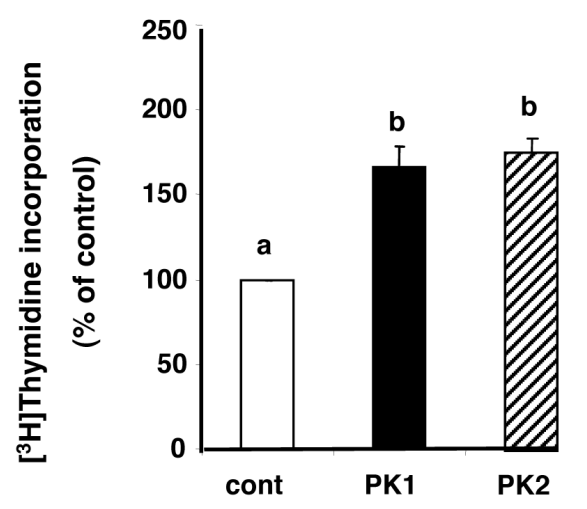

(b)

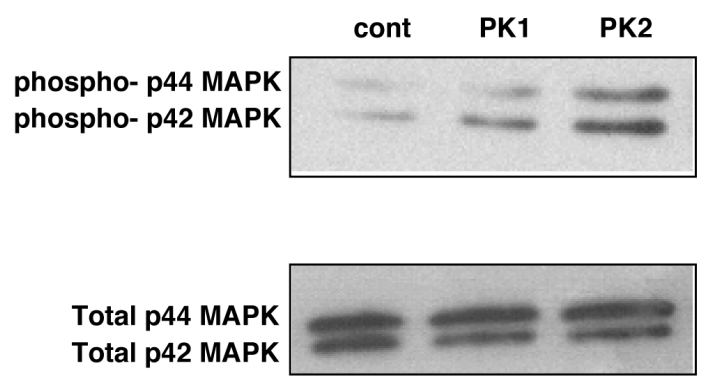

Fig. 3. Effects of $\mathrm{PKs}$ on $\left[{ }^{3} \mathrm{H}\right]$-thymidine incorporation (a) and activation of the p42/p44 MAPK pathway (b) in BAEC. For $\left[{ }^{3} \mathrm{H}\right]$-thymidine incorporation data, cells were incubated with PKs (50 nM each) for 32 hours. $\left[{ }^{3} \mathrm{H}\right]$-thymidine was added in the last 8 hours of incubation. the results were normalized to the respective control. Data represent means \pm SEM from 5 independent experiments. Means with no common letters (a-b) differ significantly $(\mathrm{p}<0.05)$. For PK induction of $\mathrm{p} 42 / \mathrm{p} 44$ MAPK cells were treated with PKs (100 nM) for 5 min and then subjected to Western blot analysis with anti-phospho/totalp42/44 MAPK. A representative blot (one of three similar ones) is shown.

cell functions including cell proliferation [25]. We observed that both PKs induced the phosphorylation of p44/42 MAPK in BAEC (Fig. 3 b) and in LEC [13].

Since PKs were shown to act as survival factors, it was interesting to examine whether conditions known to induce apoptosis in EC (serum withdrawal and TNFa exposure) modified the expression of PK-R1 in EC. Withdrawal of serum reduced PK-R1 levels by $50 \%$ in

Podlovni/Ovadia/Kisliouk/Klipper/Zhou/Friedman/Alfaidy/Meidan 
Fig. 4. Regulation of PK-R1 expression by serum withdrawal and TNF $\alpha$ in LEC and BAEC. Cells were incubated in medium containing different concentrations of serum $(10 \%$ and $0.1 \%)$ with or without TNF $\alpha(10 \mathrm{ng} / \mathrm{ml})$ for 48 hours. PK-R1 mRNA expression levels were determined by Real-Time PCR. Data represent the means from 5 independent experiments \pm SEM. Means with no common letters (uppercase for LEC and lowercase for BAEC) differ significantly $(\mathrm{p}<0.05)$.

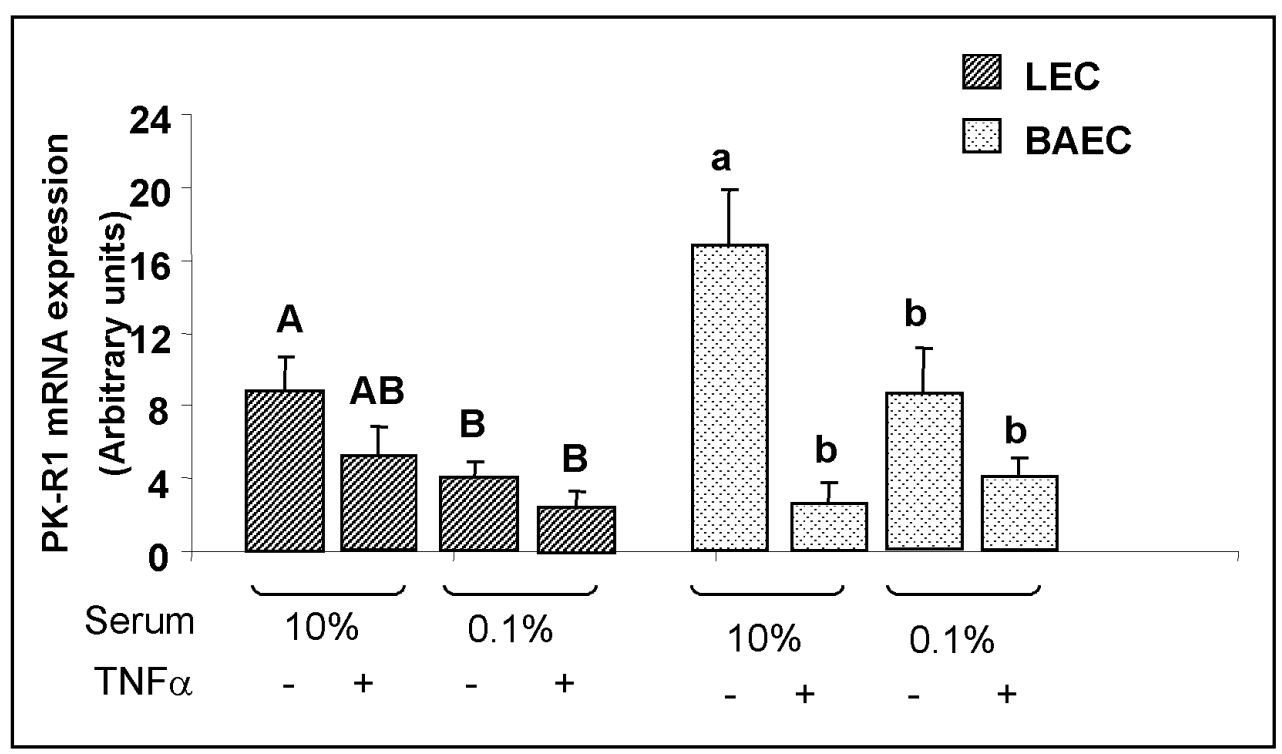

Fig. 5. Immunohistochemical localization of PK1 in bovine midcycle CL and aorta. Immunohistochemistry was performed on PFA-fixed sections. Immunoreactivity is observed in smooth muscle cells (SMC) of small arteries present in the $\mathrm{CL}(\mathrm{C}, \mathrm{E})$ and in SMC bundles of the aorta (A). Faint labeling is observed in steroidogenic luteal cells (SC, panel E). Staining was absent from endothelial cells (EC; panel E). No specific staining was observed when the primary antibody was omitted (B, D). Images were photographed at magnification x $100-400$ as indicated.

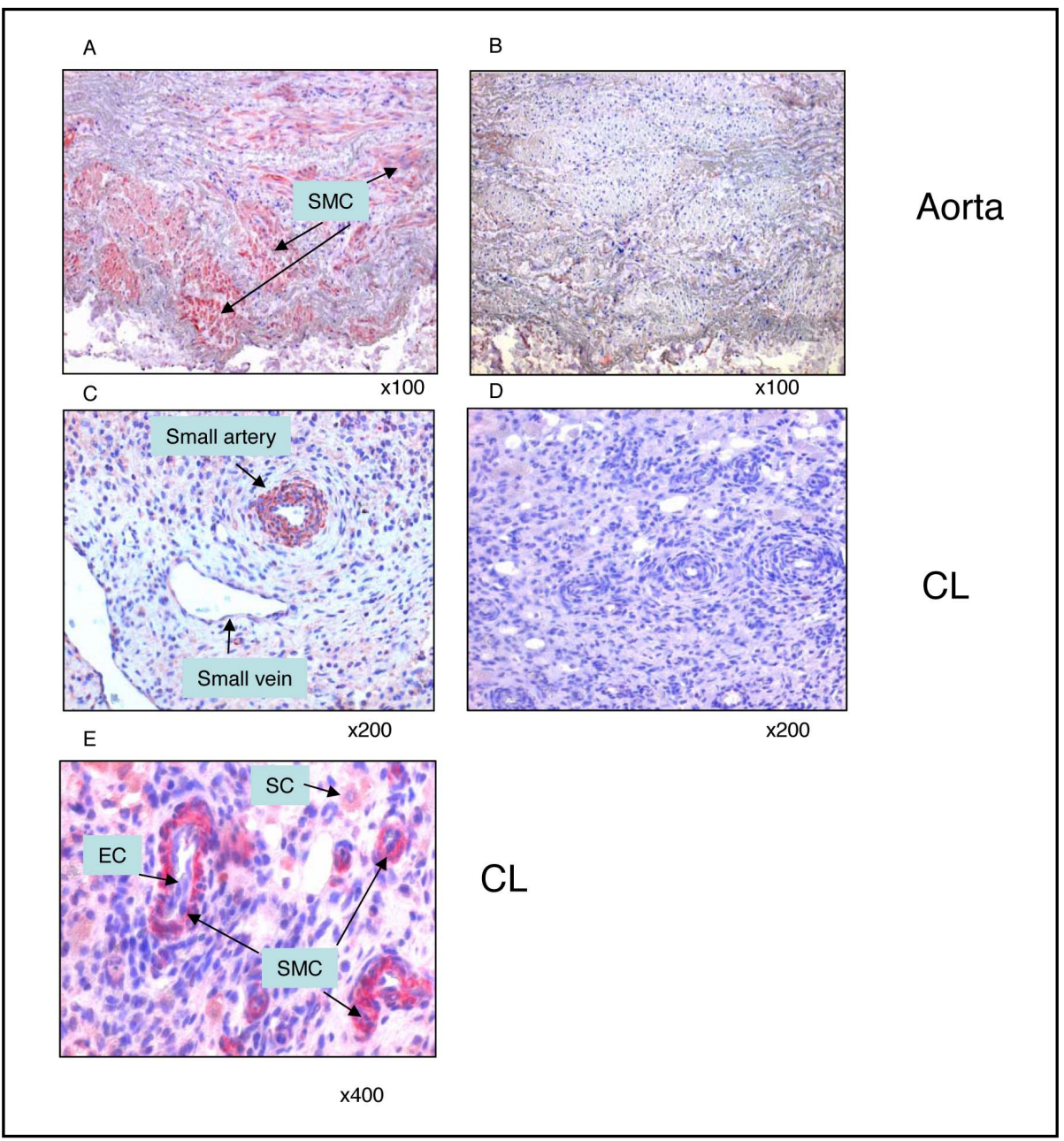

both LEC and BAEC (Fig. 4). However, in the presence of serum, TNF $\alpha$ markedly diminished (by six fold) PK$\mathrm{R} 1$ expression in BAEC only. The addition of TNF $\alpha$ in the absence of sera did not further reduce PK-R1 in

Prokineticins and Endothelial Cells either BAEC or LEC (Fig .4).

To determine the cellular source of the PK1 protein for LEC and BAEC, immunohistochemical staining was performed on sections of bovine mid-cycle CL and aorta 
Fig. 6. Effects of PKs and thrombin on the transendothelial electrical resistance (TEER) across the LEC, BAEC, and BCEC monolayers. Cells were grown on Transwell polystyrene filters until post-confluent. Twentyfour hours after incubation in medium containing $0.5 \% \mathrm{BSA}$, the cells were treated with PKs (each $75 \mathrm{nM}$ ) and thrombin $(100 \mathrm{U} / \mathrm{ml})$. Changes in resistance were measured at the time points $0,5,10,15,20,25$, and 35 minutes. Data represent the means \pm SEM from 3 independent experiments. The results were normalized to the respective control and are presented as the percent decrease in electrical resistance. Asterices indicate significant difference between treatment and the control group $(\mathrm{p}<0.05)$. (a) LEC

Thrombin

PK1

PK2

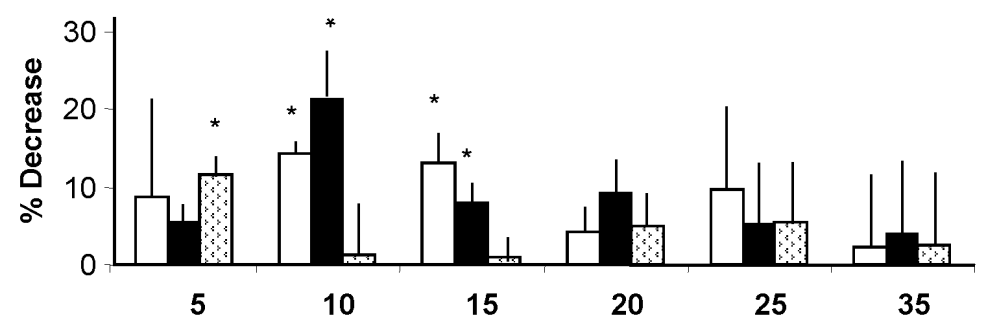

(b) BAEC

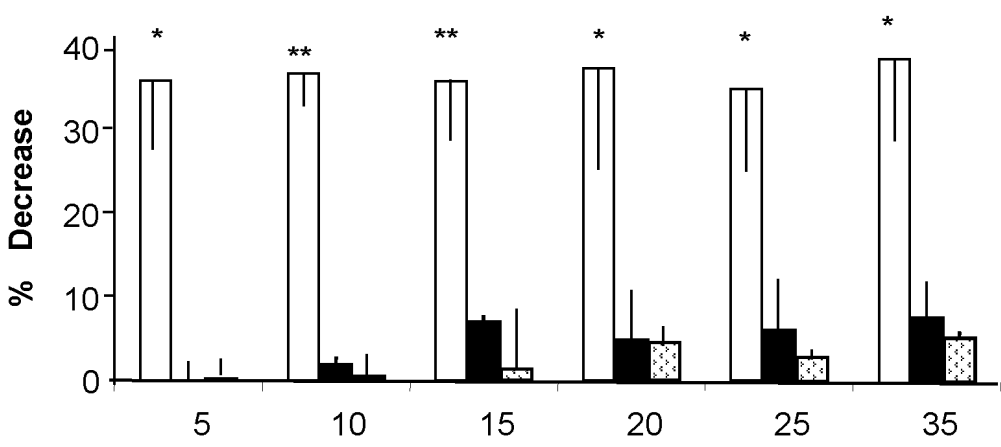

(c) BCEC

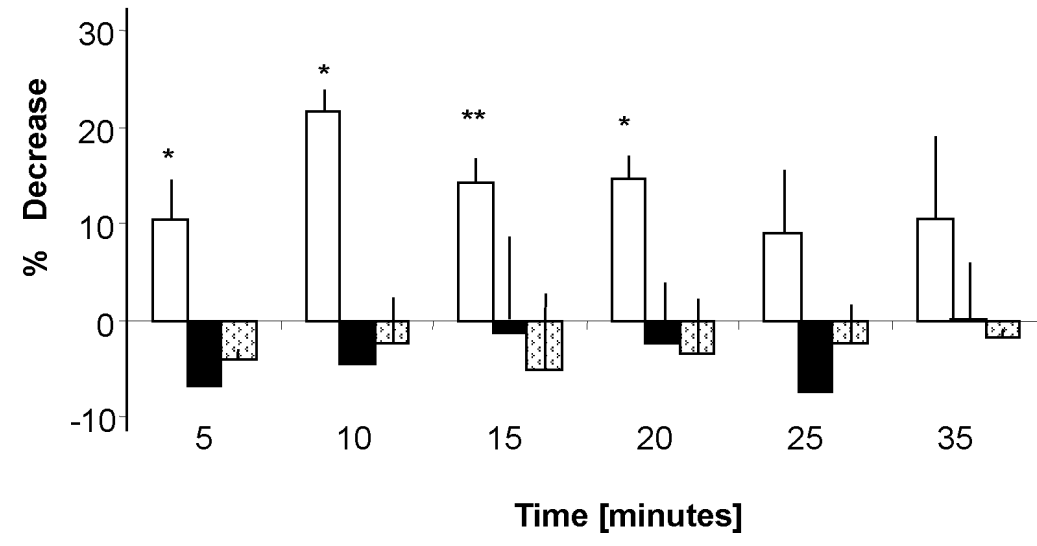

(Fig. 5). Intense immunostaining was observed in the smooth muscle cell (SMC) layers of blood vessels in the CL (Fig. 5 C, E). Luteal cells also stained but to a lesser extent (Fig. 5 E). In contrast, EC in all types of vessels remained unstained (Fig. 5 E). As observed in luteal vessels, PK1 protein was localized to SMC clusters in the aortal media and to SMC in vessels of the aortal adventitia (Fig. 5A). Staining was absent when the primary antibody was omitted (Fig. 5 B, D).

\section{Permeability Studies}

Maintenance of a semi-permeable barrier by the endothelium is critically important in endothelial cell function. We therefore examined whether PKs affected EC permeability. For these studies we used, together with LEC and BAEC, another EC type, BCEC. These cells represent an additional microvascular bed, different from that of the corpus luteum. As constituents of the blood brain barrier these cells express special features 


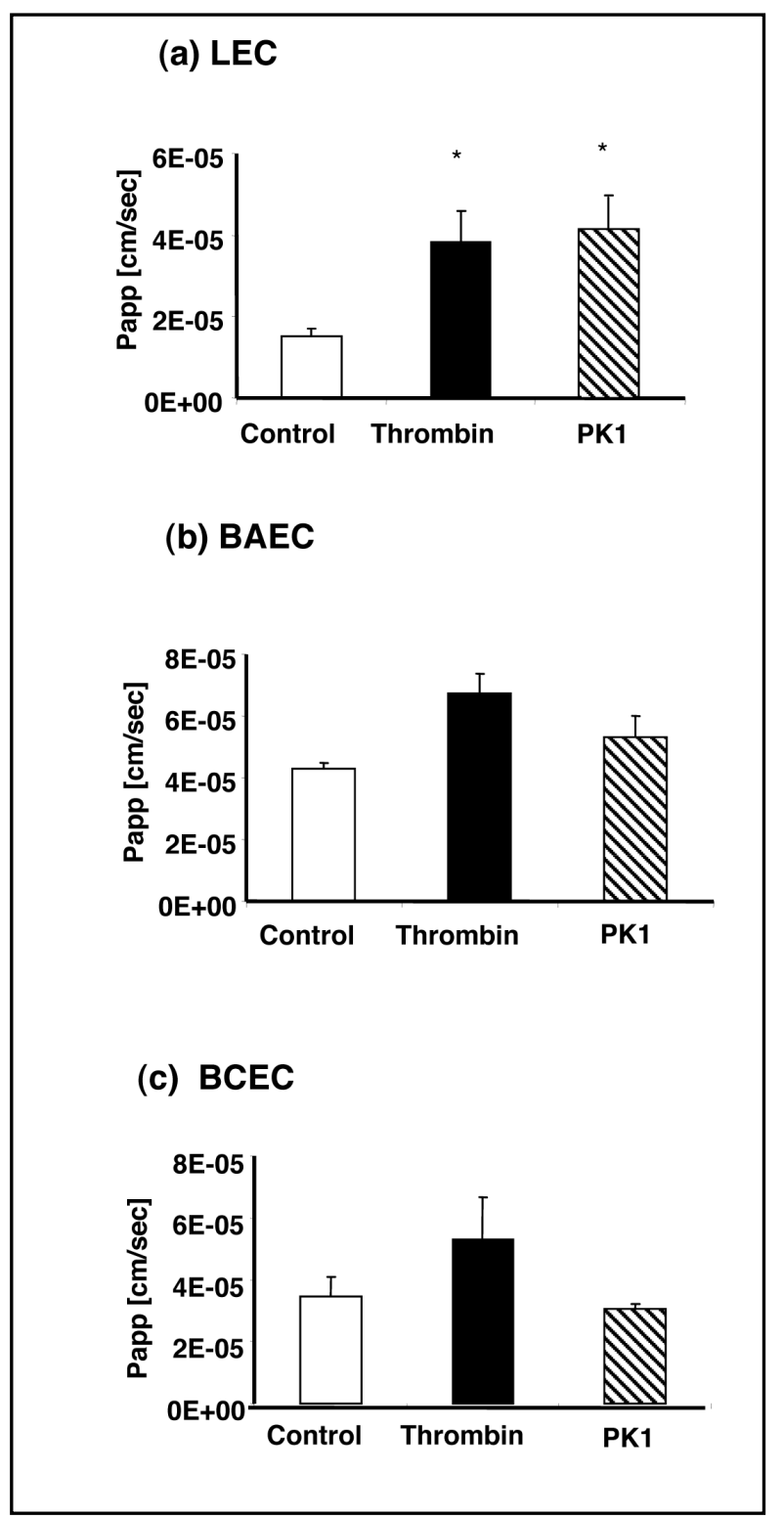

Fig. 7. Effects of PKs and thrombin on the permeability of endothelial cells to $\left[{ }^{3} \mathrm{H}\right]$ Mannitol. Cells were grown on Transwell polystyrene filters until postconfluent. Twentyfour hours after incubation in medium containing $0.5 \%$ BSA, the cells were treated with PKs (each $75 \mathrm{nM}$ ) and thrombin $(100 \mathrm{U} / \mathrm{ml})$. Following the treatments, $\left[{ }^{3} \mathrm{H}\right]$ Mannitol was added and samples from the abluminal side were removed at $5,10,15,20,25,35$, and $45 \mathrm{~min}$. The permeability coefficient was calculated as described in „Materials and Methods“. Data represent the mean \pm SEM of $n=3$ (LEC) or mean \pm range $n=2$ (BAEC, BCEC). Columns with asterices indicate significant statistical difference from control.

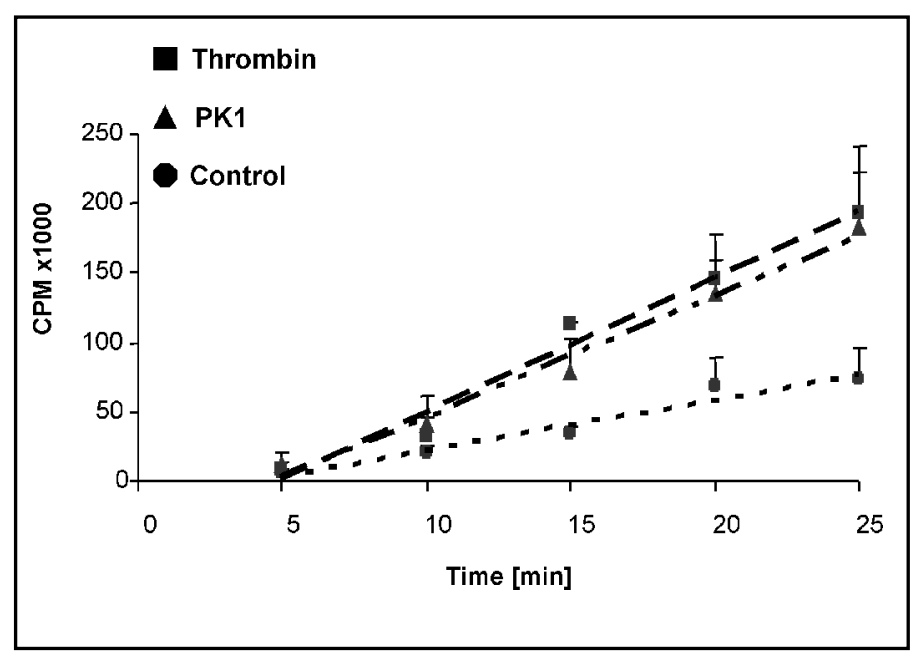

Fig. 8. A representative dQ/dT plot of $\left[{ }^{3} \mathrm{H}\right]$ Mannitol accumulation in the luminal chamber of LEC. (For details, see legend to Fig. 7).

in terms of barrier function. The endothelial barrier was evaluated by trans-endothelial electrical resistance (TEER; Fig. 6). Unlike thrombin, which enhanced electrolyte transport (reduction of TEER) in the three cell types, albeit at different rates (Fig 6a-c), PK1 decreased TEER values only in LEC, reaching a maximum already at 10 minutes after exposure to PK1 (Fig. 6a). At 15 minutes the effect declined (but remained significant) and after 20 minutes there was no further significant decrease. PK2 had a small transient effect on TEER readings only in LEC. In BCEC, PK1 appeared to increase TEER (improved the barrier function), but this effect was not statistically significant (Fig. 6c).

The data summarizing the permeability coefficients for $\left[{ }^{3} \mathrm{H}\right]$ Mannitol transport (Papp) in response to thrombin and PK1 are presented in Fig. 7. The basal permeability coefficient (Papp) in LEC was $1.7 \times 10^{-5} \mathrm{~cm} / \mathrm{sec}$ (Fig. $7 \mathrm{a})$, whereas the transport rate through BAEC and BCEC was almost twice as high, reaching values of 4.3 $\mathrm{x} 10^{-5} \mathrm{~cm} / \mathrm{sec}$ and $3.5 \times 10^{-5} \mathrm{~cm} / \mathrm{sec}$, respectively (Fig. $7 \mathrm{~b}, \mathrm{c}$ ). Thrombin almost doubled $\left[{ }^{3} \mathrm{H}\right]$ Mannitol transport through LEC. In contrast, the effect of thrombin on BAEC and BCEC was not statistically significant when compared to non-treated cells. In LEC, in a manner analogous to thrombin, PK1 markedly increased the $\left[{ }^{3} \mathrm{H}\right]$ Mannitol transport rate (Fig. 7a). In contrast, $\mathrm{PK} 1$ did not influence the transport rates in BAEC and BCEC (Fig. 7b,c). The effects of PK1 and thrombin on mannitol transport in LEC were evident already at the $10 \mathrm{~min}$ point and increased with time (Fig. 8). 


\section{Discussion}

The findings reported here and in our previous study show that PK peptides stimulated the proliferation of EC derived from vessels of either the aorta or an endocrine gland such as the corpus luteum [13]. In the two organs, PK1 was localized to SMC present in blood vessel walls and was absent from EC, suggesting a paracrine mode of action. PK1 mRNA expression was previously demonstrated in these tissues [1,26], but their specific localization to SMC is revealed here for the first time. The close functional interaction between vascular smooth muscle and endothelial cells control an array of processes such as vascular tone, angiogenesis and is of central importance in the pathogenesis of atherosclerosis and hypertension [27-30]. The particular localization of PK1 adds a new dimension to the SMC-EC interrelationship, suggesting that SMC (via PK1) may regulate the proliferation and survival of the EC lining the vessels.

Distinct expression and function was associated with PK receptors in the different EC types: luteal EC expressed both PK-R1 and PK-R2; whereas EC derived from large vessels such as aorta (BAEC) and umbilical vein EC (data not shown) only expressed receptor subtype 1. Regulation of receptor expression was also different in BAEC and LEC. Although serum removal decreased PK-R1 in both LEC and BAEC, in BAEC it was associated with a reduction of the only receptor type present in these cells, namely PK-R1. In contrast to PK-R1, serum starvation markedly augmented PK$\mathrm{R} 2$ expression in LEC [13]. Consequently, the biological effects induced by PKs were cell-specific: the addition of PKs concomitant with serum removal enhanced cell proliferation and survival of both BAEC and LEC, suggesting the involvement of PK-R1 in these functions. The mitogenic and pro-survival effects of PKs on these cells correlated with the ability of PK1 to induce phosphorylation of the p42/44 MAP kinase. However, if cells were serum-starved prior to the addition of PK1, it retained its pro-survival effect only in LEC and not in BAEC. The reason for the difference between the cells' response may be attributed to the presence of elevated PK-R2 levels in serum-starved LEC, suggesting that PKR2 can also mediate PK-induced cell survival. However, in addition to these functions, the presence of PK-R2 appears to be indispensable for PK1-induced endothelial permeability. These effects were only observed in PKR2 expressing LEC and not in BAEC or BCEC which only express PK-R1. The case of BCEC is particularly interesting: in contrast to other microvascular EC, the brain capillary endothelium serves as a protective shield or barrier between blood and the underlying tissue (central nervous system) [31, 32]. Hence, receptor distribution appears to be regulated by local physiological requirements. In fact, up till now, PK-R2 was only identified in fenestrated EC, such as those found in the adrenal cortex, CL, kidney, and liver, in agreement with notion that PK-R2 plays a role in EC permeability [10, 12, 33, 34]. Regarding PK-R1, our data tend to imply that the expression of this receptor type may enhance EC barrier function as its levels were highest in the least permeable BCEC and lowest in LEC. It is also possible that the balance between PK-R1 and R2 influences cell permeability. Indeed, these possibilities are supported by the data from our permeability studies. The decrease in TEER values and the increase in $\left[{ }^{3} \mathrm{H}\right]$ Mannitol permeability strongly suggest that PK1 (and thrombin) augment net paracellular transport in LEC. In both assays PK1 enhanced permeability in LEC and not in BAEC or BCEC. Under basal conditions microvascular luteal EC monolayers were half as permeable as monolayers from macrovascular BAEC. This is consistent with other studies that indicated that pulmonary and retinal microvascular EC formed a tighter barrier than macrovascular EC [35-37]. The short duration of PK1 and the thrombin-induced TEER reduction indicate that LEC may possess a unique capacity to repair intercellular gaps, even in the continued presence of these activators [38].

Endothelial cell structure and functional integrity are important in the maintenance of the vessel wall and circulatory function. Proinflammatory mediators such as thrombin and histamine increase vascular permeability by activating $\left[\mathrm{Ca}^{2+}\right]$ sensitive signaling pathways $[36,39]$. This change in $\left[\mathrm{Ca}^{2+}\right] \mathrm{i}$ is thought to be essential for the generation of EC paracellular gaps, thus facilitating permeability [38-40]. Activation of PK receptors leads to mobilization of calcium and stimulation of the turnover of phosphoinositide [9-11], which is consistent with the augmentation of EC permeability by PKs. Yet PKs were shown to stimulate $\left[\mathrm{Ca}^{2+}\right]$ mobilization in PK-R2 as well as in PK-R1-expressing cells, presumably through a receptor/Gq protein interaction $[9,10,41,42]$. Thus, the reason why PK1 failed to induce permeability in BAEC and BCEC expressing PK-R1 is seemingly unclear. But as PK-Rs are capable of coupling to multiple $G$ proteins [42], it cannot be ruled out that different EC expressing PK-Rs may have different $G$ protein repertoire and hence respond to PKs differently. Thus, these cells may perform

Podlovni/Ovadia/Kisliouk/Klipper/Zhou/Friedman/Alfaidy/Meidan 
distinct physiological functions in response to the same ligand stimulation. Furthermore, we reported that the two receptor types are regulated differently by stress conditions such as TNF $\alpha$, hypoxia, and serum starvation further supporting the notion that these receptors may have distinct functions [13].

As suggested by our findings, PKs act as angiogenic mitogens and survival factors for both LEC and BAEC (this study and [13]). However, this appears to contradict previous reports suggesting that PK1 acts selectively on the endothelium of endocrine glands [2]. The discrepancy might be explained by the fact that the data in the LeCouter et al. [2] study were obtained using cells that were serum-starved before adding PK1. Under these conditions, PKs maintains their effects only in LEC as was also shown in the present study. These findings highlight the importance of PK action on stressed LEC, suggesting that the presence of PK-R2 provides LEC with an additional tool to resist stress-induced apoptosis. Indeed, due to their tissue microenvironment, LEC are more prone than BAEC to experience extreme conditions such as low oxygen tension and a shortage of nutrients. This suggests that PK-induced survival is of physiological significance.

Although all vascular EC share certain common functions, it has become increasingly clear that considerable structural and functional heterogeneity exists along the length of the vascular tree and in the microvascular beds of various organs $[15,16,35]$. The molecular diversity of EC has now been established, but the origin of this heterogeneity remains poorly understood [17]. Although some genes such as E-selectin, eNOS, endothelin -1 (ET-1), and vWF are considered panendothelial, many others are expressed in a temporal and spatial manner [17]. Endothelial heterogeneity arises from cues within the tissue microenvironment [17, 43], through soluble factors and/or cell-cell contacts. For instance, we reported that freshly isolated LEC have a characteristic gene expression profile of the ET-1 system that changes upon removal of the corpus luteum microenvironment [20]. Thus EC gradually lose some of their selective characteristics. However, besides microenvironment signals that may be reversible, during development certain site-specific properties become intrinsic to the cells and are mitotically stable. Therefore, the typical expression of PK receptors in cells of different segments of the vascular tree could be an important novel element in defining the EC phenotypic heterogeneity. Collectively, these data show that both PK-R1 and PKR2 mediate PK-induced endothelial cell proliferation and survival. In addition, PK-R2 may be the receptor mediating selective microvascular responses such as increased permeability and ability to withstand stress. The full spectrum of the specific roles of PK-Rs in EC requires further research.

\section{References}

- Li M, Bullock CM, Knauer DJ, Ehlert FJ, Zhou QY: Identification of two prokineticin cDNAs: recombinant proteins potently contract gastrointestinal smooth muscle. Mol Pharmacol 2001;59:692-698.

-2 LeCouter J, Kowalski J, Foster J, Hass P, Zhang Z, Dillard-Telm L, Frantz G, Rangell L, DeGuzman L, Keller GA, Peale F, Gurney A, Hillan KJ, Ferrara N: Identification of an angiogenic mitogen selective for endocrine gland endothelium. Nature 2001;412:877884 .

-3 Kaser A, Winklmayr M, Lepperdinger G, Kreil G: The AVIT protein family. Secreted cysteine-rich vertebrate proteins with diverse functions. EMBO Rep 2003;4:469-473.

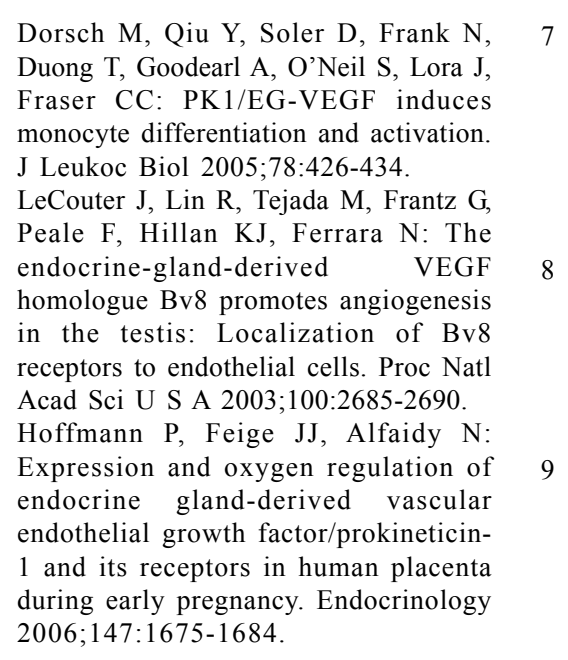

LeCouter J, Zlot C, Tejada M, Peale F, Ferrara N: Bv8 and endocrine glandderived vascular endothelial growth factor stimulate hematopoiesis and hematopoietic cell mobilization. Proc Natl Acad Sci U S A 2004;101:1681316818.

Cheng MY, Bullock CM, Li C, Lee AG, Bermak JC, Belluzzi J, Weaver DR, Leslie FM, Zhou QY: Prokineticin 2 transmits the behavioural circadian rhythm of the suprachiasmatic nucleus. Nature 2002;417:405-410.

Lin DC, Bullock CM, Ehlert FJ, Chen JL, Tian H, Zhou QY: Identification and molecular characterization of two closely related $G$ protein-coupled receptors activated by prokineticins/ endocrine gland vascular endothelial growth factor. J Biol Chem 2002;277:19276-19280. 
10 Masuda Y, Takatsu Y, Terao Y, Kumano S, Ishibashi Y, Suenaga M, Abe M, Fukusumi S, Watanabe T, Shintani Y, Yamada T, Hinuma S, Inatomi N, Ohtaki $\mathrm{T}$, Onda H, Fujino $\mathrm{M}$ : Isolation and identification of EG-VEGF/prokineticins as cognate ligands for two orphan Gprotein-coupled receptors. Biochem Biophys Res Commun 2002;293:396402.

$>11$ Soga T, Matsumoto S, Oda T, Saito T, Hiyama H, Takasaki J, Kamohara M, Ohishi T, Matsushime H, Furuichi K: Molecular cloning and characterization of prokineticin receptors. Biochim Biophys Acta 2002;1579:173-179.

- 12 Lin R, LeCouter J, Kowalski J, Ferrara $\mathrm{N}$ : Characterization of endocrine glandderived vascular endothelial growth factor signaling in adrenal cortex capillary endothelial cells. J Biol Chem 2002;277:8724-8729.

13 Kisliouk T, Podlovni H, Spanel-Borowski K, Ovadia O, Zhou QY, Meidan R: Prokineticins (endocrine gland-derived vascular endothelial growth factor and BV8) in the bovine ovary: expression and role as mitogens and survival factors for corpus luteum-derived endothelial cells. Endocrinology 2005;146:39503958.

$>14$ Michiels C: Endothelial cell functions. J Cell Physiol 2003;196:430-443.

15 Aird WC: Endothelial cell heterogeneity. Crit Care Med 2003;31:S221-230.

16 Minami T, Aird WC: Endothelial cell gene regulation. Trends Cardiovasc Med 2005;15:174-184.

17 Chi JT, Chang HY, Haraldsen G, Jahnsen FL, Troyanskaya OG, Chang DS, Wang Z, Rockson SG, van de Rijn M, Botstein D, Brown PO: Endothelial cell diversity revealed by global expression profiling. Proc Natl Acad Sci U S A 2003;100:10623-10628.

$>18$ Spanel-Borowski K, van der Bosch J: Different phenotypes of cultured microvessel endothelial cells obtained from bovine corpus luteum. Study by light microscopy and by scanning electron microscopy (SEM). Cell Tissue Res 29 1990;261:35-47.

$>19$ Fields MJ, Fields PA: Morphological characteristics of the bovine corpus luteum during the estrous cycle and pregnancy. Theriogenology 1996;45:1295-1325.

Klipper E, Gilboa T, Levy N, Kisliouk T, Spanel-Borowski K, Meidan R: Characterization of endothelin-1 and nitric oxide generating systems in corpus luteum-derived endothelial cells. Reproduction 2004;128:463-473.
Friedman A, Weiss S, Levy N, Meidan R: Role of tumor necrosis factor alpha and its type I receptor in luteal regression: induction of programmed cell death in bovine corpus luteum-derived endothelial 33 cells. Biol Reprod 2000;63:1905-1912. Dewi BE, Takasaki T, Kurane I: In vitro assessment of human endothelial cell permeability: effects of inflammatory cytokines and dengue virus infection. $J$ Virol Methods 2004;121:171-180.

Machi T, Kassell NF, Scheld MW, Lehmann GA: Effect of mannitol on the permeability of cultured endothelial cells. Fukuoka Igaku Zasshi 1996;87:178-183. Shah MV, Audus KL, Borchardt RT: The application of bovine brain microvessel endothelial-cell monolayers grown onto polycarbonate membranes in vitro to estimate the potential permeability of solutes through the blood-brain barrier. Pharm Res 1989;6:624-627.

Widmann C, Gibson S, Jarpe MB, Johnson GL: Mitogen-activated protein kinase: conservation of a three-kinase module $>36$ from yeast to human. Physiol Rev 1999;79:143-180.

26 Ferrara N, Frantz G, LeCouter J, DillardTelm L, Pham T, Draksharapu A, Giordano T, Peale F: Differential expression of the angiogenic factor genes vascular endothelial growth factor (VEGF) and endocrine gland-derived VEGF in normal and polycystic human ovaries. Am J Pathol 2003;162:18811893.

27 Shichiri M, Yokokura M, Marumo F, Hirata Y: Endothelin-1 inhibits apoptosis of vascular smooth muscle cells induced by nitric oxide and serum deprivation via MAP kinase pathway. Arterioscler Thromb Vasc Biol 2000;20:989-997.

28 Tanabe K, Tokuda H, Takai S, Matsushima-Nishiwaki R, Hanai Y, Hirade K, Katagiri Y, Dohi S, Kozawa O: Modulation by the steroid/thyroid hormone superfamily of TGF-beta- 40 stimulated VEGF release from vascular smooth muscle cells. J Cell Biochem 2006.

Veyssier-Belot C, Cacoub P: Role of $>41$ endothelial and smooth muscle cells in the physiopathology and treatment management of pulmonary hypertension. Cardiovasc Res 1999;44:274-282.

30 Zachary I, Mathur A, Yla-Herttuala S, 42 Martin J: Vascular protection: A novel nonangiogenic cardiovascular role for vascular endothelial growth factor. Arterioscler Thromb Vasc Biol 2000;20:1512-1520.

Kniesel U, Wolburg H: Tight junctions of the blood-brain barrier. Cell Mol Neurobiol 2000;20:57-76.
Abbott NJ: Inflammatory mediators and modulation of blood-brain barrier permeability. Cell Mol Neurobiol 2000;20:131-147.

LeCouter J, Lin R, Frantz G, Zhang Z, Hillan K, Ferrara N: Mouse endocrine gland-derived vascular endothelial growth factor: a distinct expression pattern from its human ortholog suggests different roles as a regulator of organ-specific angiogenesis. 2003;144:2606-2616.

34 Kisliouk T, Levy N, Hurwitz A, Meidan $\mathrm{R}$ : Presence and regulation of endocrine gland vascular endothelial growth factor/ prokineticin-1 and its receptors in ovarian cells. J Clin Endocrinol Metab 2003;88:3700-3707.

Bindewald K, Gunduz D, Hartel F, Peters SC, Rodewald C, Nau S, Schafer M, Neumann J, Piper HM, Noll T: Opposite effect of cAMP signaling in endothelial barriers of different origin. Am J Physiol Cell Physiol 2004;287:C1246-1255.

Kelly JJ, Moore TM, Babal P, Diwan AH, Stevens T, Thompson WJ: Pulmonary microvascular and macrovascular endothelial cells: differential regulation of $\mathrm{Ca}^{2+}$ and permeability. Am J Physiol 1998;274:L810-819.

King J, Hamil T, Creighton J, Wu S, Bhat P, McDonald F, Stevens T: Structural and functional characteristics of lung macroand microvascular endothelial cell phenotypes. Microvasc Res 2004;67:139-151.

Stevens T, Garcia JG, Shasby DM, Bhattacharya J, Malik AB: Mechanisms regulating endothelial cell barrier function. Am J Physiol Lung Cell Mol Physiol 2000;279:L419-422.

Tiruppathi C, Minshall RD, Paria BC, Vogel SM, Malik AB: Role of $\mathrm{Ca}^{2+}$ signaling in the regulation of endothelial permeability. Vascul Pharmacol 2002;39:173-185.

Ahmmed GU, Malik AB: Functional role of TRPC channels in the regulation of endothelial permeability. Pflugers Arch 2005;451:131-142.

Bullock CM, Li JD, Zhou QY: Structural determinants required for the bioactivities of prokineticins and identification of prokineticin receptor antagonists. Mol Pharmacol 2004;65:582-588.

Chen J, Kuei C, Sutton S, Wilson S, Yu J, Kamme F, Mazur C, Lovenberg T, Liu C: Identification and Pharmacological Characterization of Prokineticin 2 \{beta\} as a Selective Ligand for Prokineticin Receptor 1. Mol Pharmacol 2005;67:2070-2076.

LeCouter J, Ferrara N: EG-VEGF and the concept of tissue-specific angiogenic growth factors. Semin Cell Dev Biol 2002;13:3-8. 